\begin{tabular}{|c|c|c|}
\hline \multirow{3}{*}{$\begin{array}{r}\text { Case Reports in } \\
\text { Gastroenterology }\end{array}$} & \multirow{2}{*}{\multicolumn{2}{|c|}{ Case Rep Gastroenterol 2015;9:311-316 }} \\
\hline & & \\
\hline & $\begin{array}{l}\text { DOI: } 10.1159 / 000441386 \\
\text { Publisnea onine. Uctover 13, } 2015\end{array}$ & $\begin{array}{l}\text { (c) } 2015 \text { The Author(s) } \\
\text { Published by S. Karger AG, Basel } \\
\text { 1662-0631/15/0093-0311 } \$ 39.50 / 0 \\
\text { www.karger.com/crg }\end{array}$ \\
\hline
\end{tabular}

This article is licensed under the Creative Commons Attribution-NonCommercial 4.0 International License (CC BY-NC) (http://www.karger.com/Services/OpenAccessLicense). Usage and distribution for commercial purposes requires written permission.

\title{
Descending Necrotizing Mediastinitis Treated with Tooth Extractions following Mediastinal and Cervical Drainage
}

\author{
Minoru Fukuchi $^{\mathrm{a}} \quad$ Okihide Suzuki $^{\mathrm{a}} \quad$ Daisuke Nasu $^{\mathrm{b}} \quad$ Kazue Koizumi $^{\mathrm{a}}$ \\ Yu Muta ${ }^{a}$ Hideko Imaizumi $^{a}$ Toru Ishiguro ${ }^{a}$ Youichi Kumagai $^{a}$ \\ Keiichiro Ishibashi ${ }^{a}$ Erito Mochiki ${ }^{a}$ Hideyuki Ishida ${ }^{a}$ \\ Departments of ${ }^{\mathrm{a}}$ Digestive Tract and General Surgery and ${ }^{\mathrm{b}}$ Oral and Maxillofacial Surgery, \\ Saitama Medical Center, Saitama Medical University, Kawagoe, Japan
}

\section{Key Words}

Descending necrotizing mediastinitis · Drainage $\cdot$ Tooth extraction

\begin{abstract}
Descending necrotizing mediastinitis (DNM) is a rare condition in which oropharyngeal infection spreads to the mediastinum via the cervical fascia. Delayed diagnosis and surgery result in a high mortality rate among patients with DNM. We present a case of DNM resulting from odontogenic infection treated successfully with tooth extraction following mediastinal and cervical drainage. A 43-year-old, previously healthy Japanese man was admitted to our hospital for treatment of acute mediastinitis. Computed tomography revealed gas collection around the mid-thoracic esophagus and bilateral pleural effusion. We performed mediastinal drainage via right thoracotomy. Cervicotomy was performed on postoperative day 14 to drain a residual cervical abscess. The patient required the extraction of ten teeth over three procedures to address primary odontogenic infection before his fever resolved on postoperative day 40. Prompt diagnosis, aggressive drainage and removal of the source of infection can improve survival among patients with this life-threatening disease.
\end{abstract}


Fukuchi et al.: Descending Necrotizing Mediastinitis Treated with Tooth Extractions following Mediastinal and Cervical Drainage

\section{Introduction}

Descending necrotizing mediastinitis (DNM) is a mediastinal infection resulting from the spread of an oropharyngeal infection, with extension via the cervical fascial layers [1]. After the initial oropharyngeal infection, DNM often presents as an extensive deep cervical infection, with mediastinitis developing within a few days. This life-threatening condition is often misdiagnosed in its early stages because of its rarity and non-specific symptoms. Computed tomography (CT) is an invaluable tool in the diagnosis of DNM, both in the initial detection of infection and in monitoring the response to treatment [2].

Antibiotic therapy for complicated oropharyngeal infections has primarily involved penicillins and other broad-spectrum antibiotics [3, 4]. Unfortunately, the advent of antibiotics has only slightly decreased the mortality rate of DNM, which remains between 20 and $50 \%$, probably because of delayed diagnosis $[2,5]$. Prompt control of the upper airway with tracheotomy, aggressive surgical drainage of deep cervical spaces and the mediastinum as well as intravenous broad-spectrum antibiotic therapy are mandatory for successful treatment.

Several cases of DNM following tooth extraction have been reported [5-7]; however, few reports have described DNM treated with removal of odontogenic infection following mediastinal or cervical drainage $[8,9]$. We present a case of DNM resulting from odontogenic infection treated successfully with extraction of ten teeth over three procedures after mediastinal and cervical drainage.

\section{Case Report}

A 43-year-old previously healthy man was referred to our hospital for disturbance of consciousness after a 4-day history of appetite loss. Tachycardia (140/bpm), hypotension $(70 / 40 \mathrm{~mm} \mathrm{Hg})$ and a high fever $\left(39.1^{\circ} \mathrm{C}\right)$ at presentation suggested septic shock. Laboratory assays showed a white blood cell count of $3,400 / \mathrm{ml}$, a platelet count of $33,000 / \mathrm{ml}$, a blood urea nitrogen level of $58.0 \mathrm{mg} / \mathrm{dl}$, a creatinine level of $1.15 \mathrm{mg} / \mathrm{dl}$ and a C-reactive protein level of $57.8 \mathrm{mg} / \mathrm{dl}$. Blood culture grew Streptococcus constellatus sensitive to penicillins; because of the progressive infection, doripenem was chosen for its broad spectrum and administered intravenously for 12 days.

CT revealed gas collection on the right side of the mid-thoracic esophagus with bilateral pleural effusion (fig. 1a). An initial diagnosis of idiopathic esophageal perforation was made. Tube thoracostomy was performed on the left hemithorax, with drainage of $700 \mathrm{ml}$ of teacolored and purulent pleural effusion (fig. 2a). Pleural fluid culture grew $\alpha$-streptococcus. We performed mediastinal drainage via a right thoracotomy. The intraoperative diagnosis was DNM (type IIB, according to the classification of Endo et al. [10]), without perforation of the wall of the mid-thoracic esophagus, which was covered with pus (fig. $2 \mathrm{~b}$ ).

On postoperative day 4 (POD 4), repeat CT revealed a dental abscess in the root of the right maxillary canine tooth (fig. 1b). The patient was referred to the Department of Oral and Maxillofacial Surgery, where the canine tooth and three additional teeth with radicular cysts were extracted as the likely cause of DNM. The patient received a platelet transfusion at the time of extraction. Dental culture grew methicillin-resistant Staphylococcus aureus (MRSA) with sensitivity to vancomycin, which was administered intravenously for 14 days. CT also showed a residual abscess in the posterior cervical esophagus (fig. 1c). On POD 14, we performed drainage of the deep neck via cervicotomy. 
Fukuchi et al.: Descending Necrotizing Mediastinitis Treated with Tooth Extractions following Mediastinal and Cervical Drainage

The patient received antibiotic therapy with daptomycin after the 14 days of vancomycin, but his fever persisted. On POD 40, percutaneous endoscopic gastrostomy was performed to change from total parenteral nutrition to enteral nutrition. Four additional teeth with radicular cysts were removed on POD 33, followed by two more on POD 40, for a total of ten teeth extracted (fig. 3). The patient's fever subsequently resolved. On POD 41, CT revealed complete resolution of infection in the neck and thorax. The patient moved to a nearby rehabilitation hospital on POD 96 and remained healthy at follow-up examination 1 year later.

\section{Discussion}

The criteria for diagnosing DNM were defined by Estrera et al. [11] as follows: (1) clinical manifestation of severe oropharyngeal infection, (2) radiologic features of mediastinitis on CT, (3) documentation of necrotizing mediastinal infection at surgery or on postmortem examination, and (4) established relationship between oropharyngeal infection and development of DNM. Delayed diagnosis and surgery explain the high mortality rate associated with DNM [12]. However, this case confirms that DNM can progress despite the initiation of medical and surgical treatment. Early extensive and complete drainage/debridement of the cervical and mediastinal fluid collections and administration of broad-spectrum intravenous antibiotics is essential because DNM is a polymicrobial disease [11, 13]. The choice of the optimal operative procedure is determined based on the extent of infection, which is evaluated with CT $[5,14]$.

Endo et al. [10] classified DNM patients into three groups, based on the extent of infection. Type I is localized to the upper anterior mediastinum, above the tracheal bifurcation. Type IIA extends to the lower anterior mediastinum, type IIB to the posterior mediastinum. That report recommended transcervical mediastinal drainage for type I, mediastinal drainage by epigastric incision for type IIA and thoracotomy for type IIB cases. Our patient, who had type IIB DNM, underwent mediastinal drainage via thoracotomy at the initial surgery, although a transcervical approach was also required to adequately drain the deep neck. Transcervical mediastinal drainage without thoracotomy is generally inadequate. Since we judged that drainage alone would not control the cause of primary infection, tooth extraction was performed to remove the site of odontogenic infection.

DNM has been reported rarely following tooth extraction or secondary to odontogenic infection [5-9]. However, local signs are usually not as evident as poor general status, as was the case in our patient. Since extensive fascial communication exists between the gums, neck and mediastinum, odontogenic infections can rapidly spread to the mediastinum, facilitated by gravity, respiration and negative intrathoracic pressure [14]. There have been several reports of patients who required tooth extraction during hospitalization for DNM caused by an odontogenic infection $[8,9]$. Our patient required the extraction of ten teeth over three procedures before his fever resolved. To the best of our knowledge, there are no prior reports of patients requiring such prolonged dental treatment following mediastinal and cervical drainage for DNM.

DNM is a severe infection that requires prolonged treatment and long-term antibiotics and that can involve drug-resistant bacteria [15]. The agents responsible for DNM are a mixture of aerobic and anaerobic bacteria $[6,15]$. Streptococcus is the most frequently isolated anaerobic bacterium [6]. In this case, Streptococcus was detected on blood and pleural fluid culture. For these anaerobic bacteria, appropriate antibiotics are required at initial treatment. We selected doripenem for antibiotic therapy to cover both aerobic and anaerobic 
Fukuchi et al.: Descending Necrotizing Mediastinitis Treated with Tooth Extractions following Mediastinal and Cervical Drainage

bacteria. However, cases requiring prolonged infection control can develop MRSA infection over the course of treatment [15]. In our case, MRSA was detected on dental culture 4 days after the administration of doripenem. Monitoring and control of drug-resistant bacteria with frequent culture and sensitivity testing as well as administration of appropriate antibiotics are important.

In conclusion, odontogenic infection should be considered a risk factor for DNM. Despite the high mortality rate associated with this condition, prompt diagnosis, aggressive drainage, removal of the source of infection and careful postoperative care can save patients with DNM.

\section{Statement of Ethics}

All procedures followed were in accordance with the ethical standards of the responsible committee on human experimentation (institutional and national) and with the Helsinki Declaration of 1964 and later revision. Informed consent or substitute for it was obtained from the present patient for being included in the study.

\section{Disclosure Statement}

The authors have no conflicts of interest.

\section{References}

1 Makeieff M, Gresillon N, Berthet JP, Garrel R, Crampette L, Marty-Ane C, Guerrier B: Management of descending necrotizing mediastinitis. Laryngoscope 2004;114:772-775.

-2 Tsunoda R, Suda S, Fukaya T, Saito K: Descending necrotizing mediastinitis caused by an odontogenic infection: a case report. J Oral Maxillofac Surg 2000;58:240-242.

-3 Durnovo EA, Furman IV, Pushkin SY, Maslennikov IA, Bondar OG, Ivanitsky GR: Clinical results of the application of perftoran for the treatment of odontogenous abscesses and phlegmons in the maxillofacial region. J Craniomaxillofac Surg 2008;36:161-172.

-4 Warnke PH, Becker ST, Springer IN, Haerle F, Ullmann U, Russo PA, Wiltfang J, Fickenscher H, Schubert S: Penicillin compared with other advanced broad spectrum antibiotics regarding antibacterial activity against oral pathogens isolated from odontogenic abscesses. J Craniomaxillofac Surg 2008;36:462-467.

-5 González-García R, Risco-Rojas R, Román-Romero L, Moreno-García C, López García C: Descending necrotizing mediastinitis following dental extraction. Radiological features and surgical treatment considerations. J Craniomaxillofac Surg 2011;39:335-339.

6 Malis DD, Busaidy KF, Marchena JM: Lemierre syndrome and descending necrotizing mediastinitis following dental extraction. J Oral Maxillofac Surg 2008;66:1720-1725.

7 Kilic D, Findikcioglu A, Ates U, Hekimoglu K, Hatipoglu A: Management of descending mediastinal infections with an unusual cause: a report of 3 cases. Ann Thorac Cardiovasc Surg 2010;16:198-202.

8 Basa S, Arslan A, Metin M, Sayar A, Sayan MA: Mediastinitis caused by an infected mandibular cyst. Int J Oral Maxillofac Surg 2004;33:618-620.

-9 Bas B, Ozden B, Bekcioglu B, Sanal K, Yilmaz S, Celik B, Basoglu A, Celenk C: Descending necrotizing mediastinitis associated with an infected dentigerous cyst. Oral Surg Oral Med Oral Pathol Oral Radiol 2012;114:e15-e18.

$\rightarrow 10$ Endo S, Murayama F, Hasegawa T, Yamamoto S, Yamaguchi T, Sohara Y, Fuse K, Miyata M, Nishino H: Guideline of surgical management based on diffusion of descending necrotizing mediastinitis. Jpn J Thorac Cardiovasc Surg 1999;47:14-19.

11 Estrera AS, Landay MJ, Grisham JM, Sinn DP, Platt MR: Descending necrotizing mediastinitis. Surg Gynecol Obstet 1983;157:545-552.

12 Marty-Ané CH, Berthet JP, Alric P, Pegis JD, Rouvière P, Mary H: Management of descending necrotizing mediastinitis: an aggressive treatment for an aggressive disease. Ann Thorac Surg 1999;68:212-217. 
Fukuchi et al.: Descending Necrotizing Mediastinitis Treated with Tooth Extractions following Mediastinal and Cervical Drainage

13 Wheatley MJ, Stirling MC, Kirsh MM, Gago O, Orringer MB: Descending necrotizing mediastinitis: transcervical drainage is not enough. Ann Thorac Surg 1990;49:780-784.

14 Scaglione M, Pinto A, Giovine S, Di Nuzzo L, Giuliano V, Romano L: CT features of descending necrotizing mediastinitis - a pictorial essay. Emerg Radiol 2007;14:77-81.

15 Uwa N, Terada T, Saeki N, Sagawa K, Ogino K, Sakagami M: Clinical features of 5 patients with descending necrotizing mediastinitis originating from deep neck infection. Auris Nasus Larynx 2010;37:530-534.
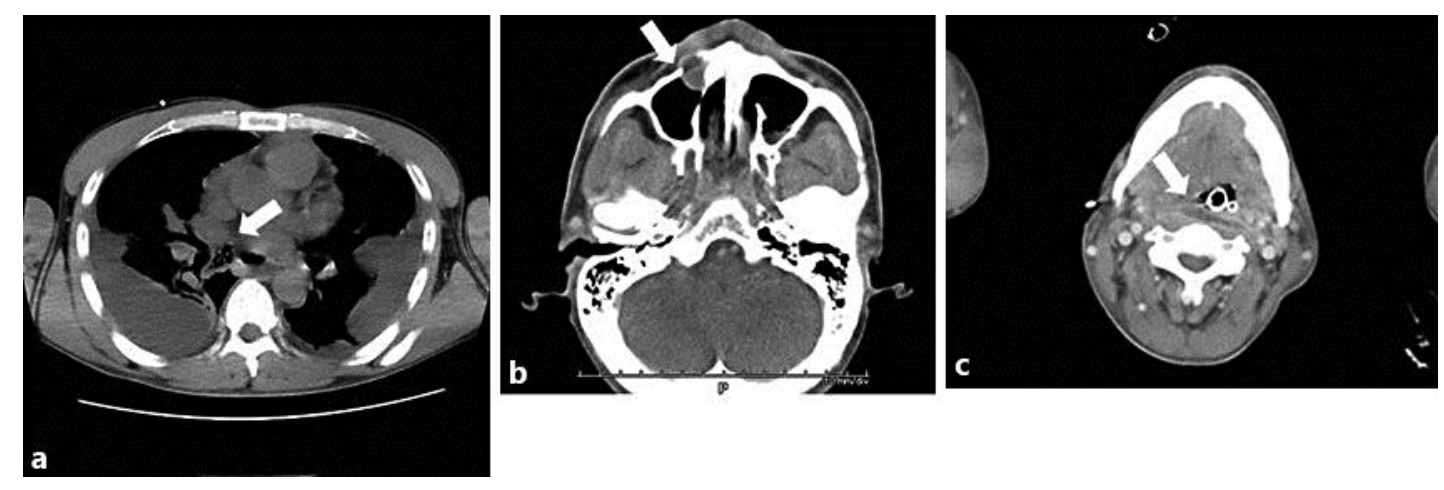

Fig. 1. CT images. a Gas collection (arrow) was observed on the right side of the mid-thoracic esophagus with bilateral pleural effusion on POD 4. b A dental abscess (arrow) was seen in the root of the right maxillary canine tooth. c A cervical abscess (arrow) was also seen in the posterior cervical esophagus on POD 4.
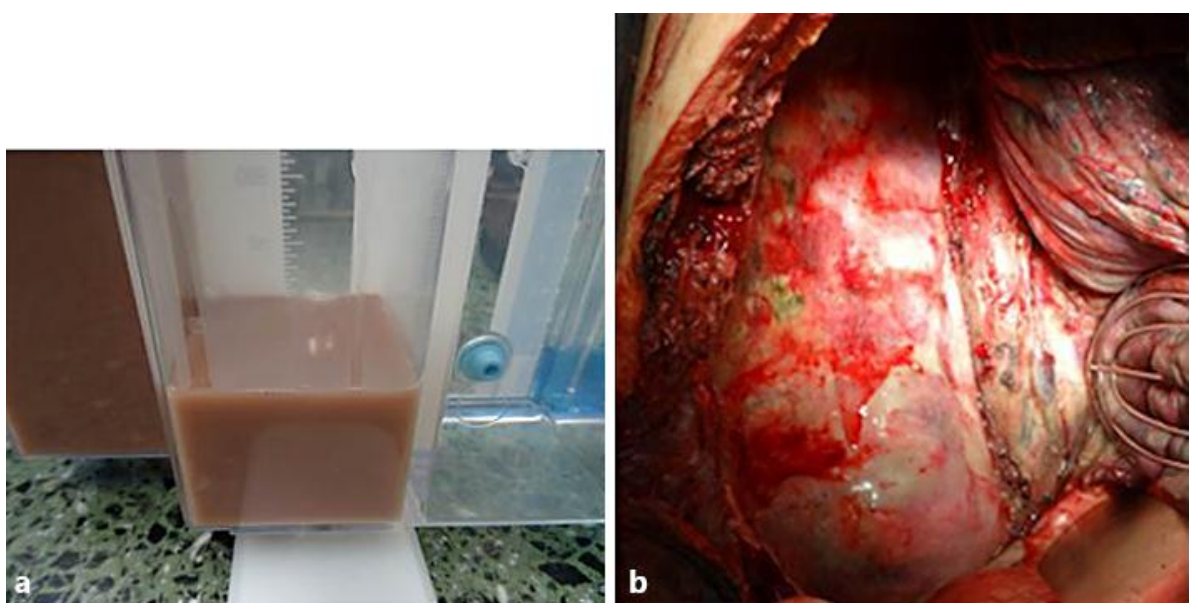

Fig. 2. Intraoperative findings. a Pleural effusion obtained from the left thoracostomy tube was teacolored and purulent. $\mathbf{b}$ During drainage of the mediastinum via right thoracotomy, the wall of the midthoracic esophagus was found to have no perforation and to be covered with pus. 


\begin{tabular}{ll|l} 
Case Reports in & \multicolumn{3}{l}{$\begin{array}{l}\text { Case Rep Gastroenterol 2015;9:311-316 } \\
\text { Gastroenterology }\end{array}$} & $\begin{array}{l}\text { ○ } 2015 \text { The Author(s). Published by S. Karger AG, Basel } \\
\text { www.karger.com/crg }\end{array}$ \\
\hline DOI: 10.1159/000441386 & &
\end{tabular}

Fukuchi et al.: Descending Necrotizing Mediastinitis Treated with Tooth Extractions following Mediastinal and Cervical Drainage

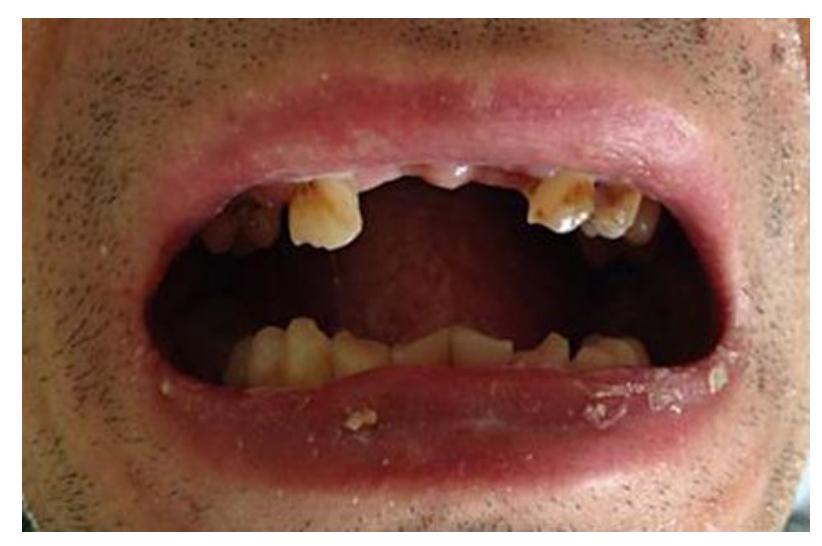

Fig. 3. Oral photograph. Ten teeth were extracted after initial surgery. 